\title{
Self-perceived Constraints of Extension Field Staff Affecting their Working Efficiency in Khyber Pakhtunkhwa, Pakistan
}

\author{
Syed Muhammad ${ }^{1 *}$, Badar Naseem Siddiqui ${ }^{2}$, Farhat Ullah Khan ${ }^{1}$ and Nawab Khan ${ }^{3}$
}

${ }^{1}$ Department of Agricultural Extension, Allama Iqbal Open University, Islamabad, Pakistan; ${ }^{2}$ Department of Agricultural Extension, PMAS-Arid Agriculture University Rawalpindi, Pakistan; ${ }^{3}$ College of Management, Sichuan Agricultural University Chengdu Campus, Wenjiang 611100, Sichuan, China.

\begin{abstract}
The responsibility of Extension Field Staff (EFS) is the dissemination of latest agricultural technologies to educate the farmers' community about how to use new applications and techniques of modern technology for the purpose to increase agricultural production. The efficiency of EFS is, therefore, reflected by the farmers' adoption level of modern recommended technology. The current study was designed and conducted during February 2018 for the purpose to find out self-perceived main constraints, affecting the efficiency of EFS in the province of Khyber Pakhtunkhwa, Pakistan. Five districts out of 26 were randomly selected one each from eastern, western, northern, southern, and central districts of the province. At second stage, two tehsils were randomly selected from each selected district for data collection. Data was collected personally through validated and pre-tested questionnaire from all the selected ten tehsils of the selected districts in which all EFS (95) respondents comprised of Field Assistants (FAs) and Agriculture Officers (AOs) served as respondents. Five-point Likert scale (Likert 1967) was used to record the response of respondents. Results showed that a majority of the respondents $(85.3 \%)$ were FAs by designation, almost half of them (50.5\%) were of middle age (> 35 to 50 years), majority (48.4\%) had education up to SSC with Diploma in agriculture, majority $(81.1 \%)$ were of rural background, and all had received trainings of different duration. Important constraints which affected the efficiency of EFS were lack of transport, political interference in transfers, large jurisdiction area, non-participation in policy decisions, unsatisfactory pay structure, unavailability of medical facilities, low opportunity of proper in-service trainings, poor linkages of agricultural extension with research wing and low social status. The Department of Agricultural Extension, Khyber Pakhtunkhwa, is advised to adopt appropriate measures to address these constraints of EFS in order to enable them to efficiently deliver their services.

Received | September 23, 2020; Accepted | November 20, 2020; Published | January 22, 2021

*Correspondence | Syed Muhammad, Department of Agricultural Extension, Allama Iqbal Open University, Islamabad, Pakistan; Email: ace. sbbu@gmail.com

Citation | Muhammad, S., B.N. Siddiqui,F.U. Khan and N. Khan. 2020. Self-perceived constraints of extension field staff affecting their working efficiency in Khyber Pakhtunkhwa, Pakistan. Sarhad Journal of Agriculture, 37(1): 64-70.

DOI | http://dx.doi.org/10.17582/journal.sja/2021/37.1.64.70

Keywords | Constraints, Extension field staff, Farmers' training, Working efficiency
\end{abstract}

\section{Introduction}

A griculture serves as the major source of livelihood for rural people in Pakistan. It is the single main sector for the economyof the countrybecause it provides industrial raw material to the agro-based industries of the country and also significantly contributes to foreign exchange earnings (UK Essays, 2018). It contributes about $18.9 \%$ of the GDP and $42.3 \%$ of the employment of workforce (GOP, 2018-19). 
Although necessary natural resources for agricultural production are abundant in the country, Pakistan still lags behind in agricultural productivity as compared to many other developing countries of the world. There is a wide yield gap in the country because actual yield is quite low than the potential yield of major crops (GOP, 2018). Low agricultural productivity may be connected to low or non-adoption of recommended agricultural technologies (Farooq et al., 2007).

The Agricultural Extension system strives to disseminate agricultural innovations to farmers and to educate them for the adoption of the disseminated techniques in order to increase their productivity (Yaseen et al., 2015). Agricultural Extension Department in Khyber Pakhtunkhwa province of Pakistan is mandated to bring desirable attitudinal change in farmers and to convince them to adopt the modern agricultural techniques aimed to uplift their socio-economic status by increasing their farm income.

Agricultural EFS play the front-line role in agricultural extension system who keeps direct contact with the end users (farmers). They also have the pivotal role to educate and motivate the farmers for adoption of recommended technologies. It means the working efficiency of agricultural EFS can be measured by the extent of adoption of innovations by the farmers (Ahmed et al., 2014).

There are many problems which prevents the effective services delivery of agricultural EFS in Pakistan. These problems may be physical, political, administrative, economic and professional in nature (Yaseen et al., 2015). Studies showed that agricultural staff was poorly trained in the Agriculture Department of the Punjab Government, Pakistan (Lodhi, 2003). It was also investigated that the office facility was not provided to the Field Assistants (FAs) at union council level and majority of the extension agents were not provided with essential teaching tools/ facilities. Physical constraints such as unavailability of transport, internet, mobile phone, and audiovideo aids affected the performance of extension field staff from an average to a great extent (Asif et al., 2014). Review studies investigated that the main problems of EFS in Pakistan were; lack of financial resources, unavailability of proper transport services, large jurisdiction area and weak coordination among relevant departments (Yaseen et al., 2015).
In comparison to previous studies, this study has used a more comprehensive model to explain the effect of the studied factors on the working efficiency of extension field staff. Specifically, this study took a broader view of the problem and includes a set of internal as well as external factors in its theoretical framework. Apart from this, the choice of unique sample is also a major contribution of this study.

\section{Objectives of the study}

1. To find out the physical, political, administrative, economic, professional and social factors affecting the working efficiency of EFS in Khyber Pakhtunkhwa, Pakistan.

2. To forward recommendations based on results for future consideration.

\section{Materials and Methods}

\section{Universe of the study}

The universe of the study was the whole province of Khyber Pakhtunkhwa, Pakistan which consists of twenty-six (26) districts. The province is situated in the Northwest of the country between $31^{\circ} 15^{\circ}$ and $36^{\circ} 57^{\circ}$ North latitude and $69^{\circ} 5^{\circ}$ and $74^{\circ} 7^{\circ}$ East longitude. The total area of the province is 74,521 square $\mathrm{km}$, with 1.88 million ha as cultivated area (Agricultural statistics of Pakistan). The climate of the province changes according to the elevation as the mountainous areas at the northern part of the province are cold in the winter and cool in the summer season and while coming towards south, the temperature increases markedly. Physical conditions of the province has also a great variation, and a major part consist of mountainous areas with agriculture as the main economic activity. The province is popular for the production of quality fruits such as apricot, apple, peaches, plums, walnuts, etc. Production of off-season vegetables during the summer months at the higher elevated areas of the province makes the province more important and increases its climatic versatility. The off-season vegetables are sold at higher prices in the big cities of the country (GOP, 2017).

\section{Selection of sample}

A multi-stage sampling technique was used in which five (5) districts were randomly selected one each from the eastern, western, northern, southern, and central districts of the province. The selected districts were: Swabi, Charsadda, Upper Dir, Karak, and 
Mardan. At second stage, two tehsils were randomly selected from each of the five selected districts and thus data were collected from the selected ten tehsils. All the agricultural EFS (95), including FAs and Agriculture Officers (AOs) serving in the selected ten tehsils, served as respondents for data collection. Out of the total EFS respondents, 14 were $\mathrm{AOs}$ and the remaining were FAs by designation.
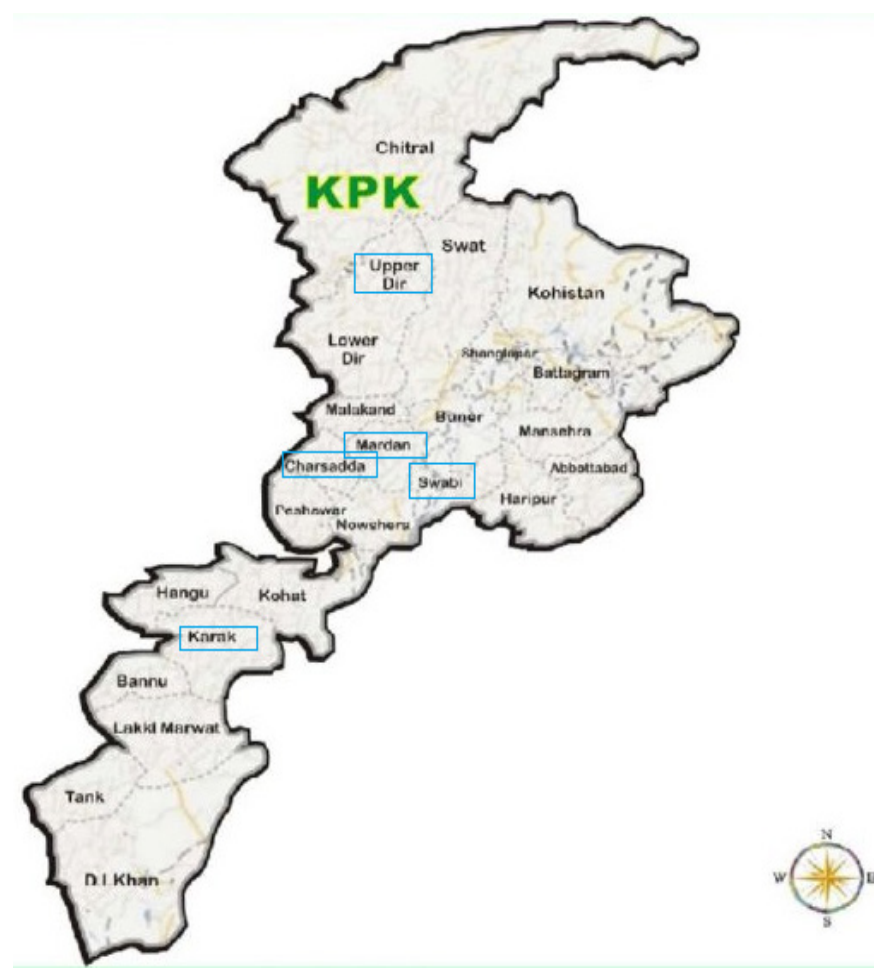

Figure 1: District wise distribution of Khyber Pakhtunkhwa on map.

\section{Data collection and information tools}

Factors affecting the performance of EFS were divided into physical, political, administrative, economic, professional, and social factors. Levels of the effect of the given factors were broadly categorized as 'no effect' and 'yes effect,' and the later was further categorized into 'very low, low, medium, high, and 'very high'. Respondents were asked about the different problems which they perceived to have affected their performance. A validated and pre-tested structured questionnaire was used for the collection of data. A five-point Likert Scale (Likert, 1967) was employed for information collection.

\section{Data analysis}

Statistical analysis was carried out by employing SPSS and descriptive statistics such as means; frequencies and weighted scores were used, and results were interpreted accordingly.

\section{Results and Discussion}

\section{Demographic characteristics of EFS}

Outcomes of the Table 1 showed that a majority of the respondents $(85.3 \%)$ were FAs by designation, almost half of them (50.5\%) were of middle age (> 35 to 50 years), majority (48.4\%) had education up to SSC with diploma in agriculture, majority (81.1 $\%)$ were of rural background, and all had received trainings of different duration.

Table 1: Demographic characteristics of the EFS respondents.

$\begin{array}{ll}\text { Age (years) } & \text { Perc } \\ \text { Up to } 35 & 21.1 \\ >35 \text { to } 50 & 50.5 \\ >50 & 28.4 \\ \text { Experience (years) } & \\ \text { Up to } 10 & 38.9 \\ >\text { > } 10 \text { to } 20 & 13.7 \\ >\text { > } 20 & 47.4 \\ \text { Designation } & \\ \text { Agriculture Officers (AOs) } & 14.7 \\ \text { Field Assistants (FAs) } & 85.3 \\ \text { Education level } & \\ \text { Secondary (SSC) with Diploma } & 48.4 \\ \text { Intermediate with Diploma } & 20.0 \\ \text { Bachelor with Diploma } & 10.5 \\ \text { Master with Diploma } & 6.3 \\ \text { M.Sc. (Hons.) Agriculture } & 13.7 \\ \text { PhD } & 1.1\end{array}$

Field of specialization

Agronomy 6.3

Agriculture Extension $\quad 2.1$

Plant Breeding and Genetics $\quad 2.1$

Horticulture 3.1

Soil and Environmental Sciences $\quad 1.0$

Training 100

Background

Rural $\quad 81.1$

$\begin{array}{ll}\text { Urban } & 18.9\end{array}$

Source: Field survey.

\section{Physical factors}

Table 2 shows the transport problem' fell in between medium' and high categories. Similarly, unavailability of technical literature, lack of internet facility, unavailability of computers and offices' location rated between low and 'medium' categories. All the 
remaining physical problems showed their existence between the categories of very low and 'low' one. The relative ranking showed that 'transport problem' with mean value 3.73 ranked $1^{\text {st }}$ followed by nonavailability of technical literature' and lack of internet facility which were respectively ranked $2^{\text {nd }}$ and $3^{\text {rd }}$ with mean values 2.87 and 2.85. Non-availability of office furniture, office stationery and lack of fax facility with mean values $1.61,1.49$ and 1.21 were ranked $8^{\text {th }}, 9^{\text {th }}$ and $10^{\text {th }}$, respectively. These results shows that 'transport problem' of EFS affect their working efficiency from medium to a high level, which needs to be addressed on priority basis, followed by 'nonavailability of technical literature' and 'lack of internet facility.

\section{Political factors}

Table 3 shows that among the political problems of EFS, transfers are placed between medium and high categories and postings/appointments and promotion between the very low and low one. The relative ranking showed that 'transfers, postings/ appointments, and 'promotion' with mean values 3.10, 1.21 , and 1.09 were respectively ranked $1^{\text {st }}, 2^{\text {nd, }}$ and $3^{\text {rd }}$.
The above results showed that posting/appointment and promotion of EFS is mainly merit-based which definitely contributes to improved working efficiency of EFS. However, the political involvement in the transfer of EFS may be discouraged for further improvement of their work efficiency.

\section{Administrative factors}

Table 4 shows that 'large jurisdiction area and 'nonparticipation in policy decisions grouped between medium and high categories and 'assignment of nonprofessional duties and lack of working coordination among staff' showed their existence between low and medium one. All the other administrative problems placed between very low and low categories. The relative ranking showed that large jurisdiction area, non-participation in policy-decisions and assignment of non-professional duties with mean values 3.32 , 3.31 , and 2.86 were respectively ranked $1^{\text {st }}, 2^{\text {nd, }}$ and $3^{\text {rd }}$. These results show that the required number of EFS may be appointed to deliver their services in time. Similarly, EFS may be involved in the process of decision-making, and their non-professional duties are minimized.

Table 2: Perception of EFS regarding effect of physical factors affecting their working efficiency.

\begin{tabular}{|c|c|c|c|c|c|c|c|c|c|c|}
\hline \multirow[t]{2}{*}{ Factors } & \multicolumn{3}{|c|}{ Response } & \multicolumn{4}{|c|}{ Level } & \multirow[t]{3}{*}{ WS } & \multirow[t]{3}{*}{ Mean } & \multirow[t]{3}{*}{ RO } \\
\hline & No & Yes & VL & $\mathrm{L}$ & Med. & $\mathrm{H}$ & VH & & & \\
\hline \multicolumn{8}{|c|}{ Percentages } & & & \\
\hline \multicolumn{11}{|l|}{ Physical factors } \\
\hline Transport & 1.1 & 98.9 & - & 1.1 & 45.3 & 31.6 & 21.1 & 351 & 3.73 & $1^{\text {st }}$ \\
\hline Residential & 22.1 & 77.9 & 35.8 & 33.7 & 6.3 & - & 2.1 & 126 & 1.70 & $7^{\text {th }}$ \\
\hline Computer & 11.6 & 88.4 & 20.0 & 44.2 & 12.6 & 6.3 & 5.3 & 188 & 2.24 & $4^{\text {th }}$ \\
\hline Telephone & 14.7 & 85.3 & 29.5 & 44.2 & 7.4 & 1.1 & 3.2 & 152 & 1.88 & $6^{\text {th }}$ \\
\hline Internet & 10.5 & 89.5 & 7.4 & 26.3 & 36.8 & 10.5 & 8.4 & 242 & 2.85 & $3^{\text {rd }}$ \\
\hline Fax & 33.7 & 66.3 & 53.7 & 11.6 & 1.1 & - & - & 76 & 1.21 & $10^{\text {th }}$ \\
\hline Office location & 15.8 & 84.2 & 18.9 & 37.9 & 24.2 & 3.2 & - & 171 & 2.14 & $5^{\text {th }}$ \\
\hline Office furniture & 18.9 & 81.1 & 43.2 & 30.5 & 4.2 & 2.1 & 1.1 & 124 & 1.61 & $8^{\text {th }}$ \\
\hline Office stationery & 15.8 & 84.2 & 51.6 & 26.3 & 5.3 & - & 1.1 & 119 & 1.49 & $9^{\text {th }}$ \\
\hline Technical literature & - & 100 & - & 21.1 & 70.5 & 8.4 & - & 273 & 2.87 & $2^{\text {nd }}$ \\
\hline
\end{tabular}

VL: Very low; L: Low; Med.: Medium; H: High; VH: Very high.

Table 3: Perception of EFS regarding effect of political factors affecting their working efficiency.

\begin{tabular}{|c|c|c|c|c|c|c|c|c|c|c|}
\hline \multirow[t]{2}{*}{ Factors } & \multicolumn{2}{|c|}{ Response } & \multicolumn{5}{|c|}{ Level } & \multirow[t]{3}{*}{ WS } & \multirow[t]{2}{*}{ Mean } & \multirow[t]{2}{*}{ RO } \\
\hline & No & Yes & VL & $\mathrm{L}$ & Med. & $\mathrm{H}$ & $\mathrm{VH}$ & & & \\
\hline \multicolumn{10}{|c|}{ Percentages } & \\
\hline \multicolumn{11}{|l|}{ Political factors } \\
\hline Transfers & 3.2 & 96.8 & - & 15.8 & 61.1 & 14.7 & 5.3 & 275 & 3.10 & $1^{\text {st }}$ \\
\hline Postings/appointments & 50.5 & 49.5 & 43.2 & 4.2 & - & 2.1 & - & 57 & 1.21 & $2^{\text {nd }}$ \\
\hline Promotion & 53.7 & 46.3 & 42.1 & 4.2 & - & - & - & 48 & 1.09 & $3^{\text {rd }}$ \\
\hline
\end{tabular}

VL: Very low; L: Low, Med.: Medium, H: High, VH: Very high; WS: Weighted score; RO: Ranked order. 
Table 4: Perception of EFS regarding effect of administrative factors affecting their working efficiency.

Factors

Response

\section{VL}

Level

WS Mean RO

\section{Administrative factors}

$\begin{array}{lllllllllll}\text { Non-professional duties } & 1.1 & 98.9 & 1.1 & 27.4 & 60.0 & 5.3 & 5.3 & 244 & 2.86 & 3^{\text {rd }} \\ \text { Non-cooperation of superiors } & 8.4 & 91.6 & 37.9 & 42.1 & 9.5 & 2.1 & - & 151 & 1.74 & 5^{\text {th }} \\ \text { Non-cooperation of colleagues } & 10.5 & 89.5 & 41.1 & 44.2 & 3.2 & 1.1 & - & 136 & 1.60 & 7^{\text {th }} \\ \text { Non-cooperation of subordinates } & 8.4 & 91.6 & 42.1 & 38.9 & 10.5 & - & - & 144 & 1.66 & 6^{\text {th }} \\ \text { Low knowledge level of training staff } & 56.8 & 43.2 & 24.2 & 16.8 & 2.1 & - & - & 61 & 1.49 & 9^{\text {th }} \\ \text { Lack of working coordination among staff } & 5.3 & 94.7 & 11.6 & 69.5 & 9.5 & 4.2 & - & 176 & 2.07 & 4^{\text {th }} \\ \text { Large jurisdiction area } & 5.3 & 94.7 & 1.1 & 3.2 & 63.2 & 18.9 & 8.4 & 299 & 3.32 & 1^{\text {st }} \\ \text { Non-participation in policy-decision } & 5.3 & 94.7 & 1.1 & 8.4 & 58.9 & 12.6 & 13.7 & 298 & 3.31 & 2^{\text {nd }} \\ \text { Unfair performance evaluation } & 22.1 & 77.9 & 63.2 & 14.7 & - & - & - & 88 & 1.19 & 8^{\text {th }}\end{array}$

VL: Very low; L: Low, Med.: Medium, H: High, VH:Very high; WS: Weighted score; RO: Ranked order.

Table 5: Perception of EFS regarding effect of economic factors affecting their working efficiency.

\begin{tabular}{|c|c|c|c|c|c|c|c|c|c|}
\hline \multirow[t]{3}{*}{ Factors } & \multicolumn{3}{|c|}{ Response } & \multicolumn{4}{|c|}{ Level } & \multirow[t]{3}{*}{ WS } & \multirow[t]{2}{*}{ Mean } \\
\hline & No & Yes & VL & $\mathrm{L}$ & Med. & $\mathrm{H}$ & VH & & \\
\hline & \multicolumn{7}{|c|}{ Percentages } & & \\
\hline
\end{tabular}

\section{Economic factors}

$\begin{array}{lllllllllll}\text { Unsatisfactory pay structure } & 2.1 & 97.9 & 1.1 & 24.2 & 55.8 & 6.3 & 10.5 & 280 & 3.01 & 2^{\text {nd }} \\ \text { Non-payment of TA/DA in time } & 5.3 & 94.7 & 5.3 & 38.9 & 38.9 & 4.2 & 7.4 & 245 & 2.68 & 3^{\text {rd }} \\ \text { Unavailability of medical facilities } & 1.1 & 98.9 & - & 9.5 & 62.1 & 14.7 & 12.6 & 311 & 3.31 & 1^{\text {st }}\end{array}$

VL: Very low; L: Low, Med.: Medium, H: High, VH: Very high; WS: Weighted score; RO: Ranked order.

Table 6: Perception of EFS regarding effect of professional factors affecting their working efficiency.

\begin{tabular}{|c|c|c|c|c|c|c|c|c|c|c|}
\hline \multirow[t]{3}{*}{ Factors } & \multicolumn{2}{|c|}{ Response } & \multicolumn{5}{|c|}{ Level } & \multirow[t]{3}{*}{ WS } & \multirow[t]{3}{*}{ Mean } & \multirow[t]{3}{*}{ RO } \\
\hline & No & Yes & VL & $\mathrm{L}$ & Med. & $\mathrm{H}$ & $\mathrm{VH}$ & & & \\
\hline & \multicolumn{7}{|c|}{ Percentages } & & & \\
\hline \multicolumn{11}{|l|}{ Professional factors } \\
\hline Incompatibility of syllabi with field situation & 9.5 & 90.5 & - & 22.1 & 55.8 & 11.6 & 1.1 & 250 & 2.91 & $3^{\text {rd }}$ \\
\hline Low opportunity of in-service training & - & 100 & - & 4.2 & 70.5 & 21.1 & 4.2 & 309 & 3.25 & $2^{\text {nd }}$ \\
\hline Low access to $\mathrm{AV}$ aids & 2.1 & 97.9 & - & 75.8 & 8.4 & 9.5 & 4.2 & 224 & 2.41 & $4^{\text {th }}$ \\
\hline Poor linkage of agric. Extension with Research wing & - & 100 & - & - & 15.8 & 47.4 & 36.8 & 400 & 4.21 & $1^{\text {st }}$ \\
\hline
\end{tabular}

Table 7: Perception of EFS regarding effect of social factors affecting their working efficiency.

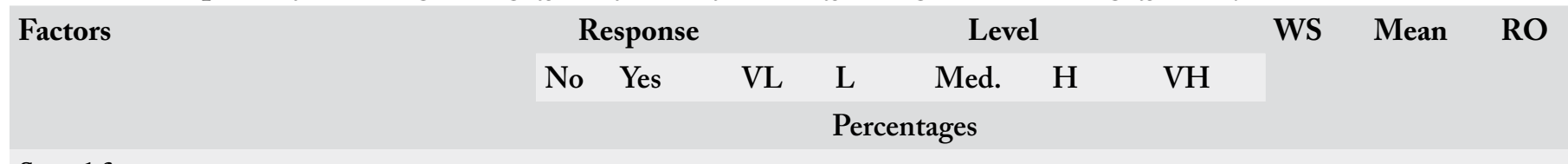

\section{Social factors}

$\begin{array}{lllllllllll}\text { Low social status } & 8.4 & 91.6 & 1.1 & 23.2 & 61.1 & 1.1 & 5.3 & 248 & 2.85 & 1^{\text {st }} \\ \text { Illiteracy/low literacy of farmers } & - & 100 & 1.1 & 53.7 & 34.7 & 9.5 & 1.1 & 243 & 2.56 & 2^{\text {nd }} \\ \text { Non-cooperation of farmers } & 2.1 & 97.9 & - & 71.6 & 21.1 & 5.3 & - & 216 & 2.32 & 3^{\text {rd }}\end{array}$

VL: Very low; L: Low, Med.: Medium, H: High, VH: Very high; WS: Weighted score; RO: Ranked order. 
Economic factors

Table 5 shows the unavailability of medical facilities' and 'unsatisfactory pay structure rated between the categories of medium and high one and 'non-payment of TA/DA in time' between 'low' and 'medium' one. Relative ranking of economic problems indicates that 'unavailability of medical facilities', 'unsatisfactory pay structure' and 'non-payment of TA/DA in time' with mean values $3.31,3.01$, and 2.68 were respectively graded as $1^{\text {st }}, 2^{\text {nd, }}$ and $3^{\text {rd }}$. It can be inferred from the above results that the 'medical facilities' and 'pay structure' of EFS may be made competitive, followed by timely processing of their TA/DA bills. The current findings have also been identified in some previous studies (Ahmed et al., 2014, 2016).

\section{Professional factors}

Table6 shows that poorlinkage of agriculturalextension with research wing was placed between high and very high categories and low opportunity of in-service training between medium and high ones. Similarly, incompatibility of syllabi with field situation' and 'low access to $\mathrm{AV}$ aids are placed between low and medium categories. Relative ranking shows' poor linkage of agricultural extension with research wing' ranked $1^{\text {st }}$ with mean value 4.21 followed by low opportunity of in-service training, and incompatibility of syllabi with field situation' with mean values 3.25 and 2.91 were respectively ranked as $2^{\text {nd }}$ and $3^{\text {rd }}$. The problem of 'poor linkage of agricultural extension with research wing' has also been highlighted as a major obstacle in previous studies (Yaseen et al., 2015). Although Table 6 shows that all EFS were trained, but their training may be insufficient due to some reasons. Similarly, incompatibility of syllabi with field situations' and 'poor access to AV aids' may be addressed so as not to hamper the efficiency of EFS.

\section{Social factors}

Table 7 shows that low social status, illiteracy of farmers and non-cooperation of farmers with EFS were rated between low and medium categories. The relative ranking shows that low social status, illiteracy of farmers and non-cooperation of farmers with EFS having mean values $2.85,2.56$, and 2.32 were respectively ranked as $1^{\text {st }}, 2^{\text {nd, }}$ and $3^{\text {rd }}$. The above results shows that the studied social factors do not affect the efficiency of EFS up to a high or very high extent. However, if these obstacles are removed or further minimized, it will improve their working efficiency.

\section{Conclusions and Recommendations}

The present research study concluded that the main constraints which affected the efficiency of EFS in the province of Khyber Pakhtunkhwa were: 'unavailability of transport facility, political involvement in transfers, large jurisdiction area, nonparticipation in policy-decisions, unavailability of medical facilities, unsatisfactory pay structure, poor linkage of agricultural extension with a research wing, low opportunity of proper in-service training and low social status.

- Government should appoint the required agriculture professionals in Agriculture Department (extension wing) so that EFS deficiency be removed.

- Governmentand non-governmentalorganizations should impart extensive in-service agricultural trainings to EFS, and their involvement should be ensured in policy formulation.

- Government should provide proper facilities to extension professionals so that young competent EFS can join the department.

- Transfer of EFS employees should be freed from political interferences.

- Government should pay attention to coordination between Agricultural extension and research wings.

\section{Novelty Statement}

Novelty of this study is using of more variables in each model to highlight significant impact on the policy formulation about agricultural extension and subsequent improvement in agricultural productivity in the KP Province.

\section{Author's Contribution}

Syed Muhammad conducted research, collected data, and wrote draft of the manuscript. Badar Naseem Siddiqui and Farhat Ullah Khan supervised the main author. Nawab Khan helped in format setting and overall improvement.

Conflict of interest

The authors have declared no conflict of interest.

\section{References}

Ahmad, N., M. Israr, K. Nawab, B.U. Khan and S. Ali. 2014. Economic incentives and satisfaction 
of the agricultural extension agents. Int. J. Agric. Ext., 2(1): 13-19.

Ahmed, M., A. Ali and J. Ali. 2016. Analysis of political factors affecting working efficiency of agricultural extension field staff in Pishin district of Baluchistan. Int. J. Adv. Res. Biol. Sci., 3(4): 58-62.

Asif, M., S. Ali, M. Ahmad, T. Ali, M. Luqman and U. Safdar. 2014. Analysis of Physical constraints affecting the efficiency of public extension agents in cotton zone of Punjab. J. Agric. Res., 52(3): 34-45.

Farooq, S., S. Muhammad, K.M. Chaudhary and I. Ashraf. 2007. Role of print media in the dissemination of agricultural information among farmers. Pak. J. Agric. Sci., 44(2): 378-380.

GoP, 2017. Pakistan bureau of statistics. http:// www.pbscensus.gov.pk/content/administrative-units.

GoP, 2018. Economic Survey of Pakistan. Economic advisor's wing finance division, Islamabad, Pakistan.

GoP, 2019. Economic survey of Pakistan. Econom- ic advisor's wing finance division, Islamabad, Pakistan.

Likert, R., 1967. The human organization: Its management and values.

Lodhi,T.E., 2003. Need for paradigm shift from top down to participatory extension in The Punjab, Pakistan: Perceptions of farmers, change agents and their supervisory staff. University of Agriculture, Faisalabad.

UK Essays, 2018. Importance of agriculture in Pakistan's economy and development. https:// www.ukessays.com/essays/economics/importance-of-agriculture-in-pakistans-economy-and-development-economics-essay. php?vref $=1$

Pervaiz, U., 2001. Main factors affecting extension activities. A case study of Malakand Agency. M.Sc (Hons.) thesis, Agric. Ext. Edu. Comm., Agric. Univ. Peshawar, Pakistan.

Yaseen, M., X. Shiwei, Y.Wen and S. Hassan. 2015. Policy challenges to agricultural extension system in Pakistan: A review. Int. J. Agric. Appl. Sci., 7(2): 23-34. 